\title{
Lived Experience as a Basis for Design: A Design Studio Kindergarten Project
}

Katja Vaghi, Tijana Vojnović Ćalić, and Anja Ohliger

\begin{abstract}
This research is motivated by our belief that artistic practices have a great potential for exchange and so can promote innovations in the creative processes. In particular, we are interested in how the corporeal lived experience can be integrated into the design process and used as a conceptual basis for an architectural design. Within this article, we propose an interdisciplinary approach to architectural design that includes somatic exercises taken from dance, and associated with a phenomenological recollection of the experiences in space. At the same time, in teaching, we recognize the challenge of bringing the design process closer to the secondsemester architecture students of the Coburg University of Applied Sciences and Arts. The research was carried out as part of a studio project which focused on the design of a kindergarten. We found that the corporeal approach to design helped the students to immerse themselves in the role of the different users, and so relate to the design in an intimate way. Consequently, the designs were surprisingly imaginative and showed a considerable variation in typology.
\end{abstract}

Keywords: Space and Movement; Architectural Design; Design Studio Project; Design Process; Memory; Corporeal Experience; Empathy; Interdisciplinarity.

\section{Introduction}

Each artistic practice develops specific approaches and procedures to achieve the desired results. These different artistic worlds sometimes meet, but often run parallel without considering the potential for mutual exchange. Considering further developments in the architectural discipline, we realize the benefits of adopting creative methods from diverse artistic disciplines to promote an interdisciplinary approach to design. Common to architecture and dance is the body in motion and the variables of space and time. Techniques used in contemporary dance can awaken the senses and 
the spatial imagination, as well as help to picture possible scenarios for the usage of space. A sensory experience of space can serve as the initial inspiration for an architectural design and become an integral part of the design process. This kind of approach has the potential to take architectural design in a different direction.

In the context of architectural education and teaching a studio project, the problem of introducing the first-year students to the design process and the search for the initial concept that guides the design stands in the foreground. Here, we recognize the significant potential in a design process that starts with the analysis of an environment they are familiar with, or the insight into their personal experience. This starting point can provide the students with the initial confidence to choose an individual design direction.

The primary aim of this article is to investigate the role of the corporeal experience within the design process and its influence on the design itself. The article describes a concrete design process that was tested with a design studio for second-semester architecture students at the Coburg University of Applied Sciences and Arts in the summer semester of 2021. The task assigned to the students was to design a kindergarten module and an assembly appropriate for children from the age of three to six years old. This project was led with the expertise of the authors - the dance researcher and movement specialist, Katja Vaghi as well as of the architects Anja Ohliger and Tijana Vojnović Ćalić.

This research, carried out as part of a studio project, deals with the question of how the corporeal lived experience could be integrated into the design process and used as a conceptual basis for an architectural design. The lived experience, in this case, refers to the memory of prior sensorimotor experiences, as well as the present experiential explorations of space intended to provide a deeper understanding of the users' needs and various sensory and emotional situations. The initial phase of the design process was to recall spatial, sensorial, and emotional childhood experiences. As the task set was to design a kindergarten, we decided that besides present embodied experiences to access and include those from the past as well. To this, the production of new experiences in the imagined roles of child or teacher was also central to the approach. Upon reflection of this teaching approach and the work with the students in the design studio, this research proposes the following hypothesis: incorporating lived experience in the design process leads to an imaginative, well-informed, and well-grounded design. Bearing 
in mind that each person experiences an individual, and therefore distinctive, spatial and sensory event, the starting point of this design process leads to the development of a range of unconventional and innovative kindergarten typologies.

\section{Theoretical Grounds}

When entering a building, the play of light and shadow, spatial configuration and sequencing, the depth of visual plans and plasticity of the various elements, and the density and quality of the materials, only to mention a few factors, are experienced through the whole of the body. Besides the visual sense, we also experience space through acoustic, olfactory, haptic, proprioceptive, and kinesthetic senses. At the beginning of their book, the scholars Joy Monice Malnar and Frank Vodvarka ask about the senses in design: »What if we designed for all our senses? (2004: IX). The focus of our pedagogical experimentation and interdisciplinary exchange is clearly expressed by Juhani Pallasmaa in his article "Architecture as Experience«, as he draws a parallel between the nature of the experience of architecture and that of art:

»Works of architecture and art are encounters and lived rather than understood intellectually. Architecture is commonly understood, taught, practiced, and evaluated primarily as a visual art form. However, we encounter buildings and environments through our entire sense of being (Pallasmaa 2018: 9).

He points to something akin to what in Maurice Merleau-Ponty's terminology would be called »bodily intentionality« (as mentioned in Hale 2017: 14) or the pre-conscious awareness that allows us to cope and function in space despite the overload of sensory information granted by our sensorial experiences. This is a state of awareness in which intellectual reasoning is yet to begin. What would the influence on planning be if this were the departing state from which to generate the main design concept?

The design studio and the introductory workshop aimed to put the experience of the users in focus and consider how they can be addressed in the design process. The methodology of the interdisciplinary workshop foregrounded a practical, embodied approach through guided experiences for the students to picture the possibilities for movements depending on the 
users' typology. The exercises allowed for the engagement of the whole body shifting the focus away from the usual catalog of activities (or the needs) that take place in space and putting the sensory experiences (or the sensorial pleasure) at the center at least in the initial phase. Taking - current or past lived embodied experiences as the departing point, stimulated the students in generating ideas beyond the general and unjustified use of geometrical forms. We asked the participants to access their memories, so past embodied lived experiences, to stimulate an empathic response to the children's point of view and experiences.

With experience, or lived experience as in Merleau-Ponty's approach, the constant exchange between the individual and the surroundings, between the perception and the actions taking place in a particular space is intended. The embodied self is considered for its possibility for actions, while, conversely, the space is seen as »a field of opportunities for action« (Hale 2017: 18). The embodied self (or agent to highlight its ability for action along with that of the passive perceiver) is thus in continuous exchange with the surroundings. The context allows for determinate movements and actions to take place. It is then for the agents to determine if these are appropriate in the context. In their design of the space, the students had to consider at least a dual approach from the users - on the one hand, the children, on the other the adults, staff members, and parents - allowing for two different sets of possibilities for embodiments to coexist (Hale 2017: 28). The module's objective was to move from phenomenology in architecture as being a form of discourse to a design method (so going against Hale's argument in 2017: 5).

As mentioned earlier, memory played an important role in connecting the students to their own experiences as children - mostly pleasurable experiences of movement and of what Bachelard calls »images of felicitous space« (Bachelard 1994[1958]: XXXV). Bachelard sees space as laden with memories and imagination. These are »spaces of intimacy« (ibid.: 12), which promote well-being and are generally associated with the childhood house. Bachelard defines them as "well-tempered matter of the material paradise«, stating: »This is the environment in which the protective beings live« (ibid.: 7). For Bachelard, memories are associated with space rather than with time: »Memories are motionless, and the more securely they are fixed in space, the sounder they are (ibid.: 9).

Depending on the complexity of the childhood house, there are usually memories and imagination attached to it - »if it has a cellar and a garret, nooks and corridors, our memories have refuges that are all the more clearly 
delineated« (ibid.: 8). In his description though, memories are not pure memories but could also be identified as daydreams in which the space is purified, devoid of all that could cause discomfort. It is, so to speak, an idealized memory that it is recalled: "memory recaptured through daydreams, it is hard to say through what syncretism the attic is at once small and large, warm and cool, always comforting (ibid.: 10). They are closely associated with dreams:

»The house we were born in is more than an embodiment of home, it is also an embodiment of dreams. Each one of its nooks and corners was a restingplace for daydreaming« (ibid.: 15).

Bachelard claims that bodily memories of this idealized space are stored in our embodied being, as Bachelard claims: "But over and beyond our memories, the house we were born in is physically inscribed in us « (ibid.: 14). Preceding language and these embodied memories and associations are inter-subjective and »communicate poetically from soul to soul« (ibid.: 17). We asked the students to recall and locate these spaces of intimacy in the house or outside the house. We started by inviting them to remember their favorite games, how they were moving while playing them and how they felt afterwards, by re-embodying them and then tracing them in sketches. We then asked them to recall spaces from their memory that they were particularly fond of. Once in contact with this archive of personal experiences they were given the task to design spatial elements, landscapes, and spaces in which the children could re-experience these states (Hale 2017:21).

\section{Why Dance and Somatics in Architecture?}

In an article entitled »Art As Action or Art As Object? The Embodiment of Knowledge in Practice As Research", the dance researcher Anna Pakes argues for an expansion of what is generally thought of as knowledge beyond the »traditional deductive or inductive logic grounding scientific thinking« to also encompass "practical reasoning " and consider »other thinking processes and forms of knowledge as equally rigorous though they do not conform to conventional logical models « (Pakes 2004). Resting her argument on the phenomenology philosopher David Carr's reflections on Aristotle's distinction »between techne (the skill of craftsmanship) and phronesis (the practical wisdom of acting well within the social and moral domains« 
(ibid.), she points to research in dance practice as relying on the latter, so that artists are exercising a certain type of "sensitivity to materials and the evolving situation" of social interactions. We would argue that this could also be extended to architects, as they are required to foresee the impact that certain materials would have on the users and furthermore anticipate exchanges among individuals, which a particular design would or would not facilitate. Dance can also be seen as intentional action, highlighting the fact that choreographers and dance researchers operating with practice are experts in mobilizing this type of practical knowledge, which is highly intersubjective. Architects can thus be seen as setting the scene for these (good) actions to take place.

The years of training that go into becoming a dancer and a choreographer grant them with a particularly refined way of perceiving movement, space, and non-verbal human interactions. It is »knowledge of «, associated with craftsmanship, rather than a »knowledge about «, associated with academia (Pakes 2009). This knowledge often remains non-verbalized. Dance is not simply dance but different dance genres foreground different types of specialization which in turn might be applied for different outcomes. Current concepts and exercises in Western theatrical dance forms and somatic processes used by dancers to fine-tune their bodies can be repurposed to propose sensory-motor experiences to the students and improve their embodied understanding of architectural and social spaces around them (we limited ourselves to Western theatrical dances but other traditions could also be considered). We draw from several different traditions in Western theatrical dance to heighten these capacities, bringing to the fore - to consciousness - what is generally intuitively understood, and thus in turn ready to be implemented into design.

\section{Somatic and Phenomenological Exploration of Motion and Space}

To allow the students to familiarize themselves with the perspective of children, the interdisciplinary workshop was composed of three sections motion, proportion, and fantasy. The classes had to be held via Zoom with short theoretical inputs that gave the students background information on particular aspects and practical exercises related to it that they could execute individually and in small groups outside. The exercises were taken from improvisation, somatic practices, and community dance activities. For example, the section on motion was divided into action and non-action (or 
rest), and the students were given a short introduction to the "movement analysis model « (1988) by dance researcher Janet Adshead Lansdale, highlighting the categories of spatial elements in a movement. They also were introduced to Rudolf von Laban's concept of kinesphere and movement dynamics in which he distinguishes eight basic movement efforts (Laban 2011[1966]). Macro and micro movements were considered in relation to the different ages that need to be accommodated in a kindergarten (from three to six years old). As we were still in partial lockdown, the students were given short films to observe the difference in the children's movement proficiency depending on their age. Considering the other parts of the workshop: the section on proportion was geared toward highlighting the problems and discomfort that one type of embodiment can experience while inhabiting a space that is not designed to consider their needs. The section on fantasy, on the other hand, considered the activities children engage in spontaneously and which foster their neurological development. This topic was also partly covered in the section on motion, as there is a significant connection between movement and brain development. The students were also asked to move beyond the category of right or wrong in their experience of the exercises so as to foreground playfulness.

The thematic units of the three consecutive workshops were combined with exercises geared toward remembering one's own experiences as a child. Behind this is Merleau-Ponty's notion that embodied experiences are not to be easily forgotten, even though they might require some time to be reaccessed. In the discussion and reflection, it became clear that the exchange with other students was particularly helpful, because the more the students shared their own experiences, the more memories seemed to emerge (pointing to remembering as a collective act). Each exercise was documented, either through pictures or drawings that were then shared on the communal digital pin board and so were easily accessible to everyone. The students were asked to describe the situation (of the exercise or memory) and their actions in a specific space, including the feelings and emotions that these actions and/or spaces brought with them.

Including subjective experiences through the description of feelings and emotions is a common activity in dance and somatic practices. We used the discussion sessions to reflect on the experience as a guide for embodied research, as this was where participants could associate a particular feeling with a particular movement or situation. During the workshop we took particular care in allowing space for this. The students were at first 


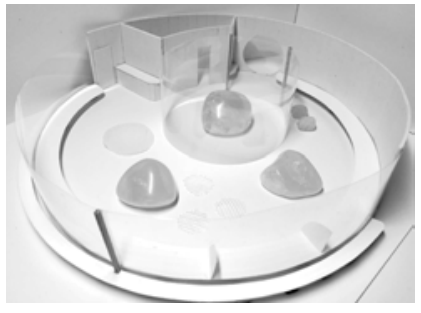

1.

Kindergarten module, Lovedeep Chauhan and Jenny Klemmer.

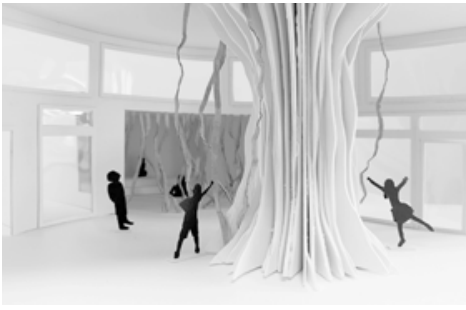

2.

Interior space of a kindergarten module, Mara Förster and Lena Markert.

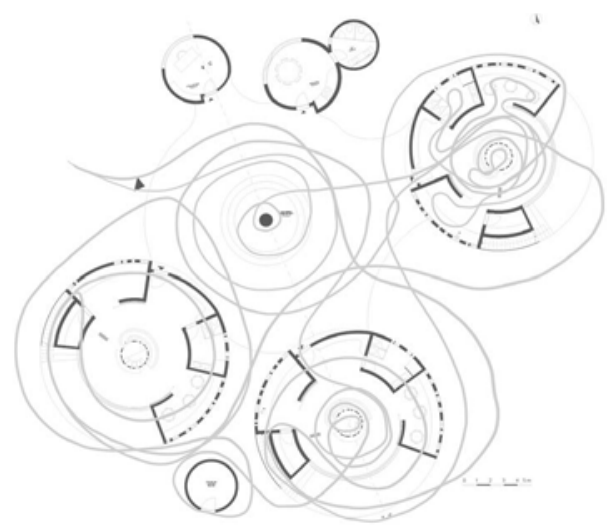

3.

Diagram of children's movement pattern, Rebecca Olimpio and Theresa Weis. 
disorientated as generally the personal experience is glossed over and dismissed as not important as relative to the individual. Instead, the phenomenological approach gives credit to the individual's experience as representative of a plurality (of some sort as variations of this experience are valid for a small group). The workshop thus became a mixture of playful individual exercises and collective remembering.

\section{Designing Spaces}

Inspired by the interdisciplinary workshop, students in pairs designed two conceptually related simple spatial elements - one to be used for activity (physical activity) and one for non-activity (rest, retreat, and concentrated work). They did so by reconstructing the spatial situations that evoked sensory and emotional experiences in their childhood or those that were explored during the initial workshop and translated them into an appropriate design. In the next step, every group developed a matching pair of conceptual landscapes - one landscape for activity and one for non-activity, which could optionally be joined into one. During the design of both spatial elements and landscapes, attention was paid to the justification for and clarity of concepts and narratives, abstraction, and open associations that evoked multiple stories and images (especially those which are archetypical, such as stones, trees, and hills), multi-functionality (potentials to be interpreted and used freely in various ways), and haptic sensations. The formed pair of landscapes - playscapes, was a starting point for the interior organization of the kindergarten module as well as a conceptual basis that informed the following design decisions and determined the design principles to be pursued throughout the successive steps of this project (in terms of consistent formal expression, composition principles, and spatial organization).

Following the established concept and narrative of the landscape, it was necessary to design a spatial structure - an independent kindergarten module of 50-60 square meters for 20 children, which included the zones for activity and non-activity described above, as well as supporting functions like a cloakroom, a sanitary block and a kitchen (fig. 1, fig. 2). Particular attention was paid to the functional logic of reasonable conjunctions and the creation of appropriate relationships between the different zones. Furthermore, students were asked to design an appropriate envelope that follows the proposed concept, develops sensitive relationships between the interior and exterior spaces, and enables quality daylight and ventilation. 

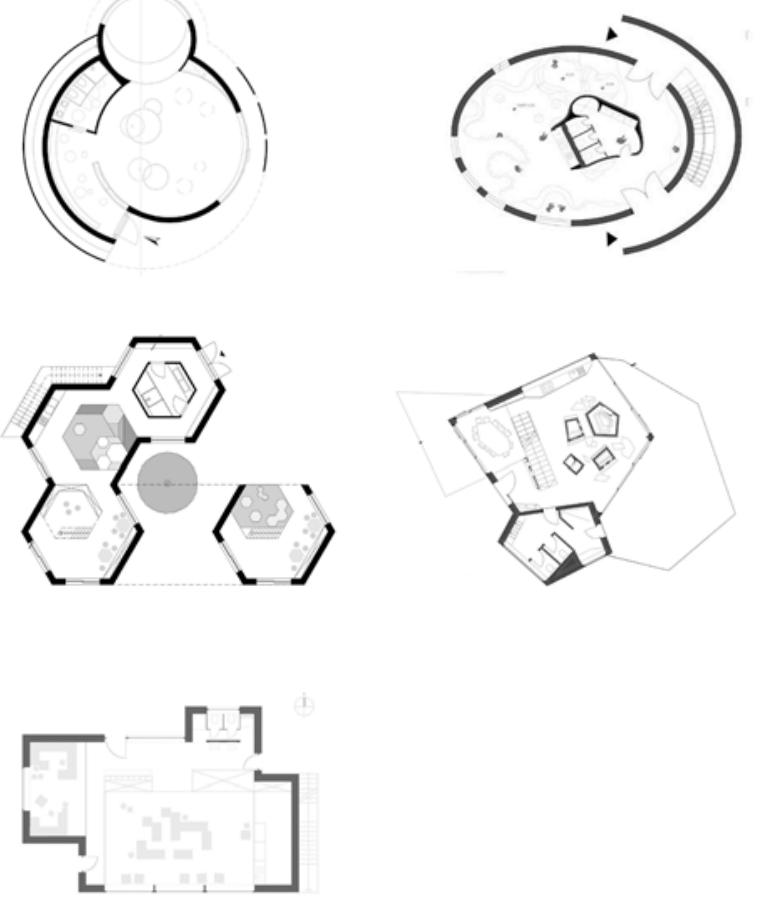

4.

Typology of the kindergarten modules, Julia Stoll and Helen Walz, Lara Geh and Juliane Graf, Leonie Hassmann and Marie Hofmann, Jessica Bauer and Sophie Fößel, Sena Akboga and Özge Yilmaz. 
This spatial structure provided the basic module for the further process of architectural assembly.

In the next step, it was necessary to form a cluster using the designed modules (and one auxiliary containing additional spaces for teachers and parents) that would finally form the kindergarten as a pavilion or enclosed structure. The kindergarten was located on the top of the individually chosen multi-story car park and otherwise designed free from the surrounding context. Here, the focus was on the overall positioning (in regard to the spatial possibilities - size and shape, of the chosen flat roof) and orientation of the structure on the car park deck (in regard to the seasonal and daily movement of the sun), as well as the organizational principles of the assembly. Further attention was paid to the functional and quality circulation areas, as well as pleasant and activated interspaces that were indicated by the various surface materialization and textures showing differentiation in their use.

To synthesize the project and their knowledge, the students were asked to illuminate their concepts through a series of diagrams. For example, to understand the movement pattern within the kindergarten cluster, it was necessary to imagine and represent possible circulation paths from the perspective of the child, the teacher, and the parent (fig. 3). The notation of imaginary movement paths was practiced through sketches and inspired by a Bauhaus exercise developed by Johannes Itten - „Figure skating on paper - avoiding points« (Holländer/Wiedemeyer 2019: 32-33) presented and practiced during the initial workshop.

All steps were accomplished using simple working mockups and drawing freehand sketches, as well as by other means of architectural representation such as plans, sections, elevations, and image-ground plans. The quality of the outer space was shown on a collage and of the interior spaces on an atmospheric photograph of the mockup. At the end of the course, we exchanged experiences with the students. During this project, which lasted a total of 4 weeks and 13 meetings, the succession of steps could be monitored on the shared digital pin board (Miro), and the interaction with students took place with the help of a virtual meeting platform (Zoom). 


\section{Results}

One of the main results of this research is the invention of a teaching method and specific design process which successfully integrated an own lived experience as the basis for design. The second-semester students reported higher motivation to work resulting from the approach that included participation, i.e. play, improvisation, intuition, and group work. They developed greater confidence in their work by relying on their own experiences, including memory and sensory experimentation, as well as on feedback from their partners. The students acknowledged the significant impact of the interdisciplinary workshop on the design. They stated that it strongly influenced the design process and determined the design focus which was based on the user's experience.

During the initial workshop, students developed intense empathy toward the users and their needs. Immersing themselves in the role of a child, then a teacher and a parent, they realized the diversity of users' needs and routines. They further recognized the spatial consequences that arise from these insights. This understanding is best reflected in the variety of spatial scales and movement diagrams.

The process and the studio project resulted in a variety of kindergarten modules and cluster typologies. The module designs limited by the precondition of a flat accessible roof took cubic, prismatic or rounded shapes as reminiscent of archetypal and abstracted images and concepts like stones, crystals, honeycombs, and trees. Nevertheless, concerning the formal expression, organic, rounded forms prevailed. The open question remains if it had something to do with the shape of the body, which was the central instrument for investigation during this design process.

The formal language of the design is well-grounded. The imagined forms mirror the inner sensorial-emotional landscape of each student. The produced designs were evaluated as consistent from the initial spatial element and landscape to the kindergarten module and assembly, following the concept idea deeply anchored in an individual's corporeal understanding of the world. 


\section{Discussion and Conclusion}

Conventionally, the architectural design is informed by means of observation, example analysis, and imagination. Exploring alternative points of departure to design, we proposed a corporeal approach. Through the phenomenological lens offered by Merleau-Ponty and Bachelard, somatic exercises taken from dance were introduced. The participatory nature of the corporeal input had a straightforward influence on the final studio designs. The initial workshop, positioned at the beginning of the course, placed the students in a playful and intuitive state through specifically devised exercises that allowed for a corporeal exploration of spatial scenarios. This shift in state resulted in a shift in their focus that foregrounded the experiential qualities of space and gave the design process a clear direction from then on.

The approach to each architectural design task implies a comprehensive understanding of the user, along with assumptions and imaginings of their requirements. Concerning our research, from the perspective of an adult, we can no longer easily understand the sensorimotor (and the cognitive) needs of children. At this initial stage, the workshop using corporeal means helped the participants to immerse themselves into this role. The performative processes triggered memories and conceptualizations, and served to collect new sets of sensations. Based on previous pedagogical experience and conversations with students, our conclusion regarding the described process is that it led, on a personal level, to a closer relationship to the project, higher motivation, noticeable conceptual independence, and on the level of design to imaginative, unconventional, and well-justified designs that are characterized by great diversity.

Concerning further research, we are interested in how and to what extent the experience and knowledge informed by the design process based on corporeal experience would stay with students and if it would change their approach to design permanently (memory plasticity). We would like to investigate how various corporeal approaches can lead to the advancement of kindergarten and other building typologies. Finally, we are interested in the development of alternative didactic methods and design processes that can be put into practice.

This study highlights how embodied knowledge can be transferred from one context to the next. This is innovative, on the one hand, in terms of understanding the design process as an activity closely linked to our everyday bodily perceptions and not somehow detached from the physical 
experience as constantly mediated by abstract models. As Pallasmaa points out: "an architectural project is not only a result of a problem-solving process« (Pallasmaa 2009: 108), since »buildings are not abstract, meaningless constructions, or aesthetic compositions, they are extensions and shelters of our bodies, memories, identities and minds « (ibid.: 117). On the other hand, from a dance studies perspective, it is extremely interesting to make the knowledge inscribed in dance available to other disciplines. As a »silent« knowledge, transmitted orally, and documented through traces, dance is enacted by the transience of the lived moving body. Dance resists the written form of the general academic discourse and necessitates alternative formats for its potential to unfold with further teasing needed for each field. The body and embodiment are still a blind spot in many disciplines, and dance can help bring this unexplored dimension to the fore. 


\section{References}

Adshead-Lansdale, Janet (1988): Dance Analysis : Theory and Practice, London: Dance Books.

Bachelard, Gaston (1958) La Poétique de l'Espace. - English translation: The Poetic of Space: The Classic Look at How We Experience Intimate Places, transl. by Maria Jolas, 1994, Boston: Beacon Press.

Hale, Jonathan (2017): Merleau-Ponty for Architects, Oxon/New York: Routledge.

Holländer, Friederike/Wiedemeyer, Nina (2019): Original Bauhaus Übungsbuch (Original Bauhaus Practice Book), Munich/ London/New York: Prestel.

Laban, Rudolf von (2011[1966]): Choreutics, edited by Lisa Ullman, Hampshire: Dance Books Ltd.

Malnar, Joy Monice/Vodvarka, Frank (2004): Sensory Design, Minneapolis: University of Minnesota Press.

Pakes, Anna (2004): »Art as Action or Art as Object? The Embodiment of Knowledge in Practice as Research «, in: Working Papers in Art \& Design, https://www.herts. ac.uk/_data/assets/pdf_file/0015/12363/ WPIAAD_vol3_pakes.pdf, accessed September 22, 2021.

Pakes, Anna (2009): »Knowing through Dancemaking: Choreography, Practical Knowledge and Practice as Research«, in: Jo Butterworth/Liesebeth Wildschut (eds.) Contemporary Choreography: $A$ Critical Reader. London: Routledge, doi: 10.4324/9780203124918
Pallasmaa, Juhani (2005): The Eyes of The Skin: Architecture of the Senses, Chichester: John Wiley \& Sons Ltd.

Pallasmaa, Juhani (2009): The Thinking Hand: Existential and Embodied Wisdom in Architecture, Chichester: John Wiley \& Sons Ltd.

Pallasmaa, Juhani (2018): »Architecture as Experience «, in: Architectural Research in Finland 2/1, 9-17.

Rogers, Brian (2017): Perception: A Very Short Introduction, Oxford: Oxford University Press.

Shilling, C. (1993): The Body and Social Theory, London: SAGE.

Tuan, Yi-Fu (1975): »Place: An Experiential Perspective«, in: Geographical Review 65/2, 151-165.

Wittmann, Franziska (2019): Körper in Räumen (Bodies in Spaces), Luzern: Quart Verlag. 
